\title{
NONLINEARITIES, FEEDBACKS AND CRITICAL THRESHOLDS WITHIN THE EARTH'S CLIMATE SYSTEM
}

\author{
JOSÉ A. RIAL ${ }^{1}$, ROGER A. PIELKE SR. ${ }^{2}$, MARTIN BENISTON ${ }^{3}$, \\ MARTIN CLAUSSEN ${ }^{4}$, JOSEP CANADELL $^{5}$, PETER COX $^{6}$, HERMANN HELD $^{4}$, \\ NATHALIE DE NOBLET-DUCOUDRÉ ${ }^{7}$, RONALD PRINN $^{8}$, \\ JAMES F. REYNOLDS ${ }^{9}$ and JOSÉ D. SALAS ${ }^{10}$ \\ ${ }^{1}$ Wave Propagation Laboratory, Department of Geological Sciences CB\#3315, \\ University of North Carolina, Chapel Hill, NC 27599-3315, U.S.A. \\ E-mail: jar@email.unc.edu \\ ${ }^{2}$ Atmospheric Science Dept., Colorado State University, Fort Collins, CO 80523, U.S.A. \\ ${ }^{3}$ Dept. of Geosciences, Geography, Univ. of Fribourg, Pérolles, Ch-1700 Fribourg, Switzerland \\ ${ }^{4}$ Potsdam Institute for Climate Impact Research, Telegrafenberg C4, 14473 Potsdam, \\ P.O. Box 601203, Potsdam, Germany \\ ${ }^{5}$ GCP-IPO, Earth Observation Centre, CSIRO, GPO Box 3023, Canberra, ACT 2601, Australia \\ ${ }^{6}$ Met Office Hadley Centre, London Road, Bracknell, Berkshire RG12 2SY, U.K. \\ ${ }^{7}$ DSM/LSCE, Laboratoire des Sciences du Climat et de l'Environnement, Unité mixte de Recherche \\ CEA-CNRS, Bat. 709 Orme des Merisiers, 91191 Gif-sur-Yvette, France \\ ${ }^{8}$ Dept. of Earth, Atmospheric and Planetary Sciences, Massachusetts Institute of Technology, \\ 77 Massachusetts Avenue, Cambridge, MA 02139-4307, U.S.A. \\ ${ }^{9}$ Department of Biology and Nicholas School of the Environmental and Earth Sciences, \\ Phytotron Bldg., Science Dr., Box 90340, Duke University, Durham, NC 27708, U.S.A. \\ ${ }^{10}$ Dept. of Civil Engineering, Colorado State University, Fort Collins, CO 80523, U.S.A.
}

\begin{abstract}
The Earth's climate system is highly nonlinear: inputs and outputs are not proportional, change is often episodic and abrupt, rather than slow and gradual, and multiple equilibria are the norm. While this is widely accepted, there is a relatively poor understanding of the different types of nonlinearities, how they manifest under various conditions, and whether they reflect a climate system driven by astronomical forcings, by internal feedbacks, or by a combination of both. In this paper, after a brief tutorial on the basics of climate nonlinearity, we provide a number of illustrative examples and highlight key mechanisms that give rise to nonlinear behavior, address scale and methodological issues, suggest a robust alternative to prediction that is based on using integrated assessments within the framework of vulnerability studies and, lastly, recommend a number of research priorities and the establishment of education programs in Earth Systems Science. It is imperative that the Earth's climate system research community embraces this nonlinear paradigm if we are to move forward in the assessment of the human influence on climate.
\end{abstract}

\section{Introduction}

Nonlinear phenomena characterize all aspects of global change dynamics, from the Earth's climate system to human decision-making (Gallagher and Appenzeller, 1999). Past records of climate change are perhaps the most frequently cited examples of nonlinear dynamics, especially where certain aspects of climate, e.g., 
the thermohaline circulation of the North Atlantic ocean, suggest the existence of thresholds, multiple equilibria, and other features that may result in episodes of rapid change (Stocker and Schmittner, 1997). As described in Kabat et al. (2003), the Earth's climate system includes the natural spheres (e.g., atmosphere, biosphere, hydrosphere and geosphere), the anthrosphere (e.g., economy, society, culture), and their complex interactions (Schellnhuber, 1998). These interactions are the main source of nonlinear behavior, and thus one of the main sources of uncertainty in our attempts to predict the effects of global environmental change. In sharp contrast to familiar linear physical processes, nonlinear behavior in the climate results in highly diverse, usually surprising and often counterintuitive observations, so it is important, before embarking on the discussion of data, that we agree on a few basic characteristics of nonlinear climate.

\subsection{LINEAR AND NONLINEAR SYSTEMS}

Even an elementary description of Earth's climate system must deal with the fact that it is composed of the above subsystems all interconnected and open, allowing fluxes of mass, energy and momentum from and to each other (see Figure 1). Since the Earth itself is a closed system, these fluxes eventually cycle through, so that outputs re-enter the system to become inputs, creating feedbacks and feedback chains. Eventually, each subsystem affects the response of every other subsystem and of the climate as a whole. It is this cross talk among the different parts of the climate that engenders the disproportionate relations between input and output typical of a nonlinear system. The phrase 'the whole is more than the sum of its parts' underscores the failure of the principle of superposition in a nonlinear system such as the climate. In sharp contrast, where superposition is valid the whole is exactly equal to the sum of its parts. The system is linear and there is no cross talk; each part behaves as if it were acting alone.

How do we tell when there is nonlinearity in the climate we observe? There are at least three important observable characteristics that separate linear from nonlinear systems, all of which are exemplified in the data to be discussed.

(1) While linear systems typically show smooth, regular motion in space and time that can be described in terms of well-behaved, continuous functions, nonlinear systems often undergo sharp transitions, even in the presence of steady forcing. These transitions usually result from crossing unstable equilibrium thresholds (e.g., abrupt climate change, as described by Alley et al., 2003).

(2) The response of a linear system to small changes in its parameters or to changes in external forcing is usually smooth and proportionate to the stimulation. In contrast, nonlinear systems are such that a very small change in some parameters can cause great qualitative differences in the resulting behavior (chaos) as suggested for instance by fluid dynamic models of atmospheric convection (Lorenz, 1963). 


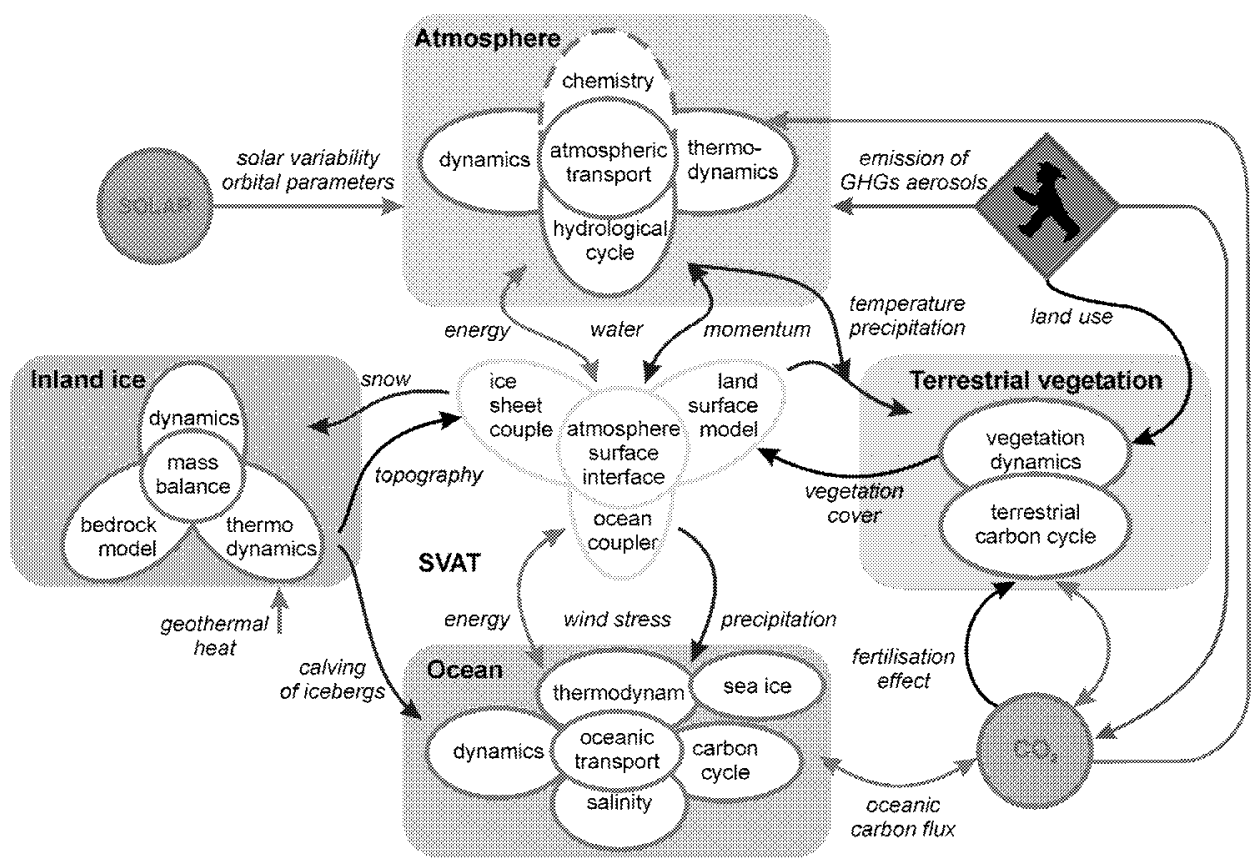

Figure 1. Structure of CLIMBER-2, an Earth System Model of Intermediate Complexity (EMIC; Claussen et al., 2002). The model consists of four modules which describe the dynamics of the climate components atmosphere, ocean, terrestrial vegetation, and inland ice. These components interact via fluxes of energy, momentum (e.g., wind stress on the ocean), water (e.g., precipitation, snow, and evaporation), and carbon. Also, the land-surface structure is allowed to change in the case of changes in vegetation cover or the emergence and melting of inland ice masses, for example. The interaction between climate components is described in a so-called Soil Vegetation Atmosphere Transfer Scheme (SVAT). CLIMBER-2 is driven by insolation (which can vary owing to changes in the Earth orbit or in the solar energy flux), by the geothermal heat flux (which is very small, but important in the long run for inland ice dynamics), and by changes imposed on the climate system by human activities (such as land use or emission of greenhouse gases (GHG) and aerosols).

(3) After transients dissipate, an oscillatory linear system's frequency always equals that of the forcing, while the spectral response of a nonlinear system to oscillatory external forcing usually exhibits frequencies not present in the forcing (such as combination tones), phase and frequency coupling, synchronization and other indications of nonlinearity often detected in past climate data (e.g., Pisias et al., 1990).

\subsection{CHAOS AND COMPLEXITY}

Thus, nonlinearity gives rise to unexpected structures and events in the form of abrupt transitions across thresholds, unexpected oscillations, and chaos (Kaplan and Glass, 1995). Actually, the climate system is not only chaotic, it is also 'complex' (Rind, 1999), in the sense that it is composed of many parts whose 
interactions can, through a process still not completely understood (Cowan et al., 1999), provoke spontaneous self-organization and the emergence of coherent, collective phenomena that can be described only at higher levels than those of the individual parts (Goldenfeld and Kadanoff, 1999). Therefore, it is useful to establish for clarity's sake that chaos and complexity are different aspects of nonlinear response. Chaos refers to simple systems that exhibit complicated behavior, such as the intricate time series produced by a dripping faucet, the unpredictable oscillations of a double pendulum, or the random behavior of populations in models of logistic growth (May, 1976). Conversely, complexity refers to complicated systems that exhibit simple, so-called emergent behavior. For instance, in the highly complex tectonic-geologic subsystem, the emergent behavior is an earthquake, in the world economy, a stock market crash, and in the biosphere, a massive extinction. In the climate system, abrupt climate change is a likely example of unpredictable emergent behavior. In fact, observations indicate that the climate system is, and has been for millions of years, riddled with episodes of abrupt change, ranging form large, sudden global warming episodes (e.g., the end of the last ice age), to drastic and rapid regional changes in the hydroclimatic cycle, precipitation and aridity (e.g., the expansion of the Sahara). Because of their obvious importance in understanding future climate trends, these and other examples of abrupt climate change are discussed in this paper.

Within the climate system chaotic behavior exhibits sensitive dependence to initial conditions, confinement and typical aperiodicity. This is to say that tiny differences in initial states can exponentially blow up to big differences in later states, but the values of the relevant variables remain confined within fixed boundaries, never exactly repeating. In the climate system, and as we shall soon discuss, plausible examples of chaos are ENSO (El Niño, Southern Oscillation) and NAO (North Atlantic Oscillation). In fact, simple deterministic models that exhibit chaotic behavior qualitatively reproduce the irregular oscillations of ENSO for strong coupling between ocean and atmosphere (e.g., Tziperman et al., 1994). ENSO may in fact be chaotic in the sense that the equatorial Pacific climate may flip in a chaotic way (randomly) from one to another of its three preferred quasi-stable states (normal, La Niña, El Niño).

\subsection{FEEDBACKS AND THRESHOLDS}

Although chaotic dynamics and emergent properties may be surmised from data interpretation and from the comparison of data to models, feedbacks are the only climate processes whose presence and effects can often be quantified and, in some cases understood with almost certainty. In this paper we illustrate how the presence of several types of amplifying (positive) and controlling (negative) feedbacks, some physical (ice sheet-albedo interaction), some biogeophysical (albedo-vegetation interaction), and some biogeochemical (anthropogenic gases-atmosphere interaction) can be deduced from observations. Feedbacks are the most likely processes behind 
most of the nonlinearities in the climate. The relatively stable global temperature and benign climate the earth has enjoyed for billions of years is testimony to the action of regulating negative feedbacks which balance and neutralize amplifying (explosive) positive feedbacks continuously (e.g., Watson and Lovelock, 1984). It is quite likely that such a continuously active regulating feedback mechanism failed to develop in Venus, leading to the present hellish environment of its surface. We can then imagine that nature has arranged things in such way that on Earth, and on the average, the net climate-driving feedback is negative, slightly stronger than the net positive feedback, at least for small values of some (external or internal) forcing. It is when the forcing grows to a point in which the positive feedback takes over that its explosive amplification produces the nonlinear effects that we see in the data. Thus, a critical threshold may in fact be the point at which the two competing feedback effects are just balanced. Since there are countless feedbacks and thresholds, rapid amplification of potentially exploding variables becomes highly probable, and sharp, abrupt climate change should then be the norm, as appears to be suggested by the past records of climate change. We must emphasize however that there is as yet no basic understanding of abrupt climate change (Clark et al., 2002).

\subsection{PAPER ORGANIZATION}

The goal of this paper is to discuss key issues and questions related to nonlinearity in the Earth's climate system and its implications in global climate change research. First, we discuss examples of nonlinear climate response from observations of abrupt climate change detected in both pre-historic and recent time series (Examples 2.1-2.5). Next we discuss models of coupled ocean and atmosphere mediated by chaotic dynamics (Examples 3.1-3.2). Finally we look at nonlinearities in the carbon cycle and the effects of biogeochemical feedbacks in models of present and future climate change (Examples 4.1-4.4).

After the examples, we address scale and methodological issues as related to some of the challenges in predicting the consequences of human actions on the Earth's climate system. For example, given the nearly certain occurrence of sudden transitions between climate states, is 'prediction' per se achievable? We suggest an alternative - and highly robust - approach using integrated assessments within the framework of vulnerability studies, the details of which we then discuss and justify. To conclude we provide a series of recommendations for research priorities, including elucidating potential sources of nonlinearity, identifying key feedbacks and linkages in the Earth's climate system, and establishing Earth Systems Science programs in order to provide the next generation of scientists a more complete view on this crucial topic. 


\section{Nonlinearity, Abrupt Climate Change and Feedbacks in Past and Present Climate Time Series}

\subsection{THE NONLINEAR PACEMAKER OF THE ICE AGES}

Nature has been performing climate experiments for millions of years, and many of the results are recorded in deep-sea sediments and ice cores (e.g., Cronin, 1999). It is therefore important that we begin our discussion describing paleoclimate data to provide a historical perspective. As we shall see, the paleoclimate records suggest a strongly nonlinear, complex climate system.

The ice ages of the Pleistocene are remarkable quasi-periodic events of past global climate change. At their peak global mean temperature was over $4{ }^{\circ} \mathrm{C}$ lower than today, and enormous ice sheets several kilometers thick covered most of northern North America and Eurasia. However, the records of the ice ages are far from understood, mostly because the response of the climate to the presumed forcing (secular changes in Earth's orbital eccentricity, spin axis, and precession) appears to be strongly nonlinear. For instance, it is well known that while the main driving frequency of the ice ages is about $100 \mathrm{ky}$ ( $1 \mathrm{ky}=1,000$ years) the timing between consecutive glacial periods has been steadily increasing from $\sim 80 \mathrm{ky}$ to $\sim 120 \mathrm{ky}$ over the last $\sim 500$ ky (Raymo, 1997; Petit et al., 1999). This feature, plus the near absence of a large response at the strongest eccentricity forcing period (413 ky) and the presence of significant variance at frequencies not present in the orbital forcing, are strong evidence of nonlinearity in the climate's response to orbital forcing (e.g., Nobes et al., 1991; Ghil, 1994). To explain these nonlinear features, Rial (1999) introduced the idea that the climate system transforms the astronomically amplitude-modulated insolation into frequency modulated fluctuations of global ice mass. This is frequency modulation entirely analogous to the electronic process by which the frequency of a carrier signal is changed in proportion to the amplitude of a relatively lower frequency signal, as in FM radio and television broadcasting. Many well-known properties of FM signals are in fact fully consistent with features of the paleoclimate data that have puzzled researchers for years, such as the above mentioned varying duration of the ice age cycle, the presence of combination tones of orbital frequencies, and perhaps the most telling, the apparent absence of spectral power at $413 \mathrm{ky}$ (Imbrie et al., 1993).

Frequency modulation is a phase- and frequency-locking process that transfers energy from one frequency band into another, and creates new frequencies (called sidebands) as combination tones of the carrier and the modulating frequencies, and thus a good example of nonlinear cross talk among the frequencies that make up the response. 


\subsection{THE MID-PLEISTOCENE CLIMATE SWITCH}

Around $950 \mathrm{ky}$ ago, a prominent switch in the frequency response of the climate system to orbital forcing occurred. This phenomenon, usually called the mid-Pleistocene transition (MPT), resulted in a change from the $41 \mathrm{ky}$ predominant glaciation period to a new $\sim 100$ ky period, without a corresponding change in the forcing orbital frequencies, as shown in Figure 2a. Though a number of explanations have been proposed, the MPT continues to be one of the most puzzling examples of the nonlinear character of climate response. Figure $2 \mathrm{a}$ clearly shows that the oscillatory response of the climate switches frequency and amplitude at about $950 \mathrm{ky}$ ago while the forcing is essentially the same throughout. Mudelsee and Schulz (1997) estimate the ice mass to have increased by about $1.05 \pm 0.20 \times 10^{19} \mathrm{~kg}$, equivalent to an ice sheet area expansion of $3.1 \pm 0.7 \times 10^{12}$ $\mathrm{m}^{2}$ and thickness of up to $3 \mathrm{~km}$. Such a large increase in ice extent (and ice topography) must have created a new atmospheric circulation pattern and new feedbacks to maintain the new, unprecedented climatic conditions (longer glaciations and greater, thicker ice caps). A probable clue to the origin of the MPT is the fact that around one million years ago the mean long-term trend of the insolation dropped slightly to a new mean (Berger and Loutre, 1991). The corresponding decrease in mean global temperature, amplified by feedbacks, could have shifted the climate system's sensitivity to forcing at lower frequency. The transformation of a mean temperature step-like drop into a switch to a much lower resonant frequency is a clear example of nonlinear response, consistent with the previously mentioned transformation of amplitude modulation into frequency modulation.

\subsection{ABRUPT WARMING EPISODES IN THE PALEOCLIMATE RECORD}

Paleoclimate records over many time scales exhibit episodes of rapid, abrupt climate change, which may be defined as sudden climate transitions occurring at rates faster than their known or suspected cause (Rahmstorf, 2001). Abrupt climate change is believed to be the result of instabilities, threshold crossings and other types of nonlinear behavior of the global climate system (Clark et al., 1999; Alley et al., 1999; Rahmstorf, 2000), but neither the physical mechanisms involved nor the nature of the nonlinearities themselves are well understood. Figure $2 b$ shows selected examples of abrupt climate change in the form of rapid warming episodes followed by much slower cooling episodes. Each warming/cooling sequence usually repeats at nearly equal time intervals, giving the time series a characteristic quasi-periodic saw-tooth appearance that, remarkably, appears at multiple time scales (as shown in the enlargement) and displays an unclear relation to astronomical forcing.

Throughout most of the paleoclimate proxy data from sediments and ice cores, there is a frequent repetition of this same theme; abrupt and fast warming (sometimes lasting only a few decades) followed by much slower cooling. This is a pattern that, having happened often in the past, will likely happen in the future, 
MPT

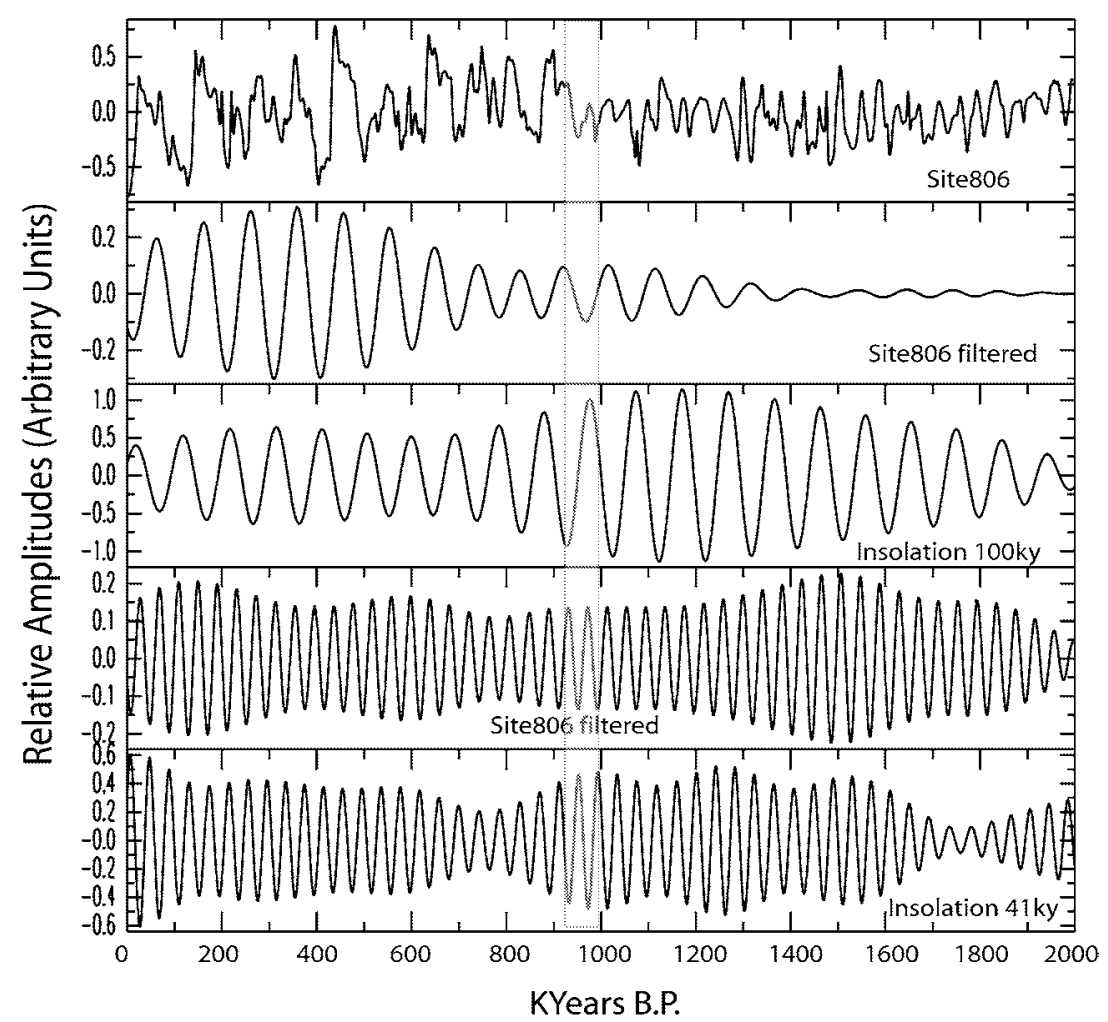

Figure 2a. Examples of nonlinearities in the paleoclimate. The mid-Pleistocene transition (MPT). The global ice volume proxy shows a sudden change in predominant frequency around 950 ky ago. The top panel shows the data (Site 806), the next two panels show (top trace) the result of filtering the data with a narrow band-pass filter centered at $100 \mathrm{ky}$ and below it the corresponding astronomical forcing (insolation) filtered in the same manner. The lower two panels show a similar comparison but for a filter centered at $41 \mathrm{ky}$. The longer period records reflect the selective nonlinearity of the system, as the response to $100 \mathrm{ky}$ forcing is negligible for times earlier than $1 \mathrm{Ma}$, and after that it becomes strong, without a corresponding change in the forcing. No similar relation is seen in the short periods. (Modified from Clark et al., 1999; Mudelsee and Schulz, 1997).

which makes compelling evidence for the urgent need to improve our understanding of the physical processes involved. By itself, Figure $2 \mathrm{~b}$ already provokes a number of obvious and stimulating questions, such as, why are warming episodes generally so much faster than cooling ones (saw-tooth)? How can rapid climate change be triggered by slow change in orbital parameters? Does self-similarity of response mean similarity of processes regardless of timescale? What nonlinear processes are at work? Could the present rate of anthropogenic warming trigger one of those abrupt, huge warming events of the last ice age?

The Dansgaard-Oeschger (D/O) oscillations of the last glacial shown in Figures $2 \mathrm{~b}$ and $3 \mathrm{a}$ are among the clearest examples of abrupt warming episodes 


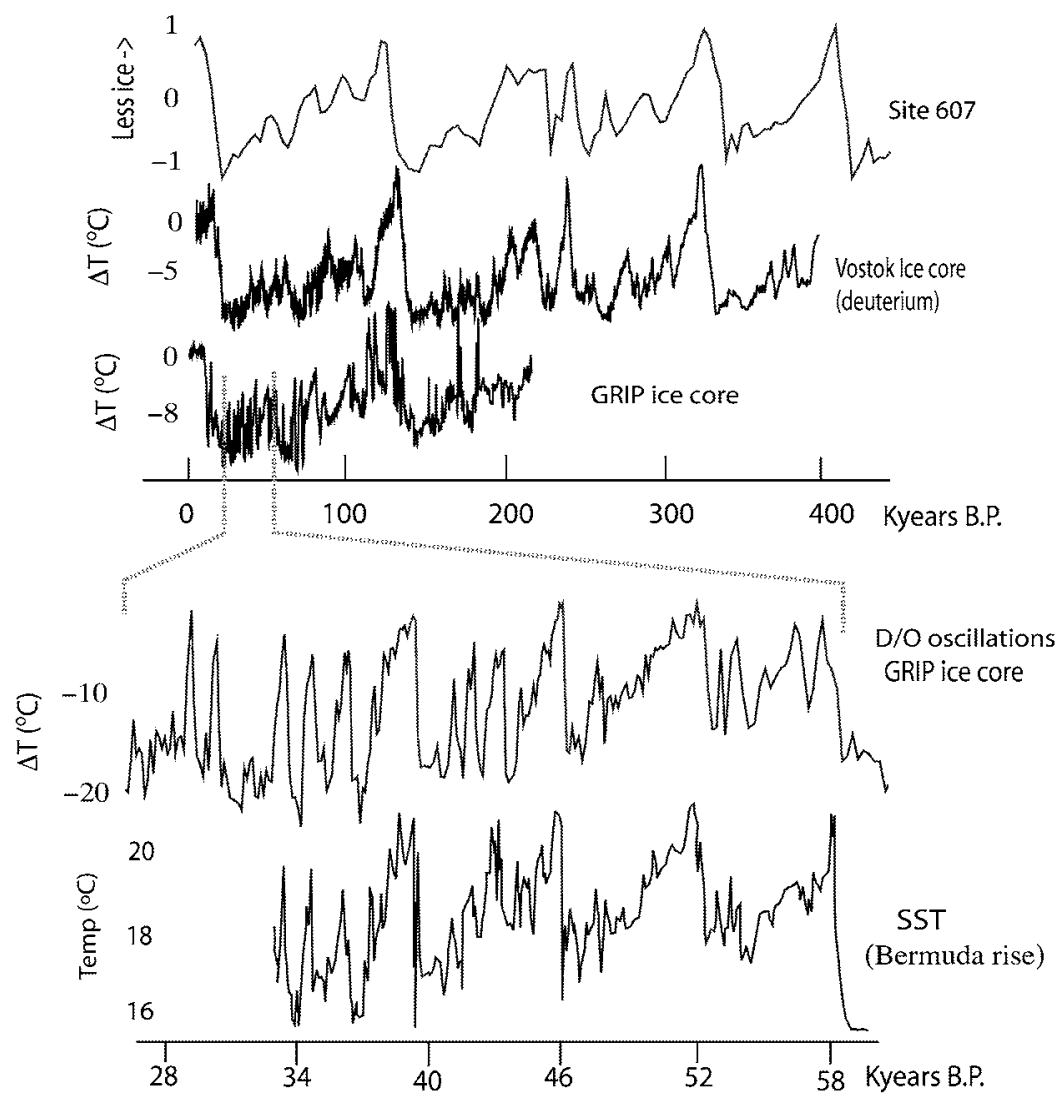

Figure $2 b$. Samples of climate change across different time scales and proxy records (stable isotopic ratios) for global temperature and ice volume, including SST (sea surface temperature) deep-sea sediment (Site 667) and ice cores (Vostok, GRIP). Note the typical saw-tooth shape which, created by the fast warming/slow cooling sequences, appears to be independent of time scale, displaying an intriguing self-similarity. Main warming periods are indicated by vertical light gray stripes. Also, note the close similarity between the temperature oscillations in Greenland and in the sub-tropics (Bermuda) (data taken from Raymo, 1997; GRIP Project Members, 1993; Petit et al., 1999; Sachs and Lehman, 1999).

(regional temperature in Greenland increased suddenly by up to $10^{\circ} \mathrm{C}$ in just a few decades and on multiple occasions). The climate was indeed highly variable during glacial times and switched abruptly and frequently between cold and warm modes. Ganopolski and Rahmstorf (2001) proposed the following mechanism. The present-day climate state is characterized by a warm (switched-on) mode of the thermohaline circulation (THC) being interpreted as an equilibrium state of the underlying dynamics. Although a second stable state exists for the present-day climate (see Figure 3b) representing a mode leading to much colder temperatures over northern Europe (switched-off THC), a transition between the two has not occurred during the Holocene because of the relatively large basin of attraction of 
the warm mode. Quite the contrary, during the last glacial period, a stable (cold) and a marginally unstable (warm) mode existed for the dynamics of the THC with a much smaller basin of attraction for the cold mode. Utilizing CLIMBER 2.3, a climate model of intermediate complexity (whose framework is illustrated in Figure 1), it can be shown that a relatively small perturbation of the freshwater input at high latitudes is sufficient to switch the system into the marginally unstable mode whose lifetime is of the order of several hundred years. A sinusoidal modulation with amplitude much smaller than the boundaries F1/F2 in Figure 3b does not induce switching in the present-day climate but does result in periodic switching under glacial conditions. Preliminary results indicate that in the presence of noise, this driving amplitude can be further reduced, resulting in a flipping behavior typical of the nonlinear effect called stochastic resonance (Ganopolsky and Rahmstorf, 2001). Finally, the D/O events can be explained if a mild periodic forcing (of unknown origin) of the THC plus noise is assumed. This external trigger becomes amplified due to the coexistence of a stable state and a marginally unstable mode in the THC system. Such coexistence is impossible in a linear system; hence, nonlinearity is a necessary condition for switching behavior.

\subsection{THE ABRUPT DESERTIFICATION OF THE SAHARA}

Paleoclimatic reconstructions suggest that during the Holocene climate optimum (9000-6000 years ago), North Africa was wetter and the Sahara was much smaller than today (Prentice et al., 2000). Annual grasses and shrubs covered the desert, and the Sahel reached as far as $23^{\circ} \mathrm{N}$ (Claussen et al., 1999), over $500 \mathrm{~km}$ north of its present location. During the Holocene optimum a slightly increased tilt of the Earth's spin axis and perihelion in July led to stronger insolation of the Northern Hemisphere during summer thereby strengthening the North African summer monsoon (Kutzbach and Guetter, 1986). However, the North African climate is sensitive to changes in land surface's albedo, which can result from vegetation removal. In fact, Charney and Stone (1975) recognized that high albedo resulting from vegetation removal can enhance desert expansion by reducing rainfall, which further reduces vegetation, in a strong, desert-expanding positive biogeophysical feedback. This mechanism offers a possible explanation for climate changes in the Sahara and particularly for increased drought in the Sahel and its southward migration in late Holocene. Actually, when using present-day land-cover as initial condition, models based solely on atmospheric processes do not yield an increase in precipitation large enough to lead to a substantial reduction in the Sahara 6000 years ago (Joussaume et al., 1999). However, when feedbacks between atmosphere and vegetation are incorporated, the models simulate a vegetation distribution in good agreement with paleobotanic reconstructions (Claussen and Gayler, 1997; deNoblet-Ducoudre et al., 2000; Doherty et al., 2000). Summarizing, precessional forcing led to an enhancement of the African monsoon, creating conditions that were then amplified mainly by atmosphere-vegetation feedbacks, and to a lesser 


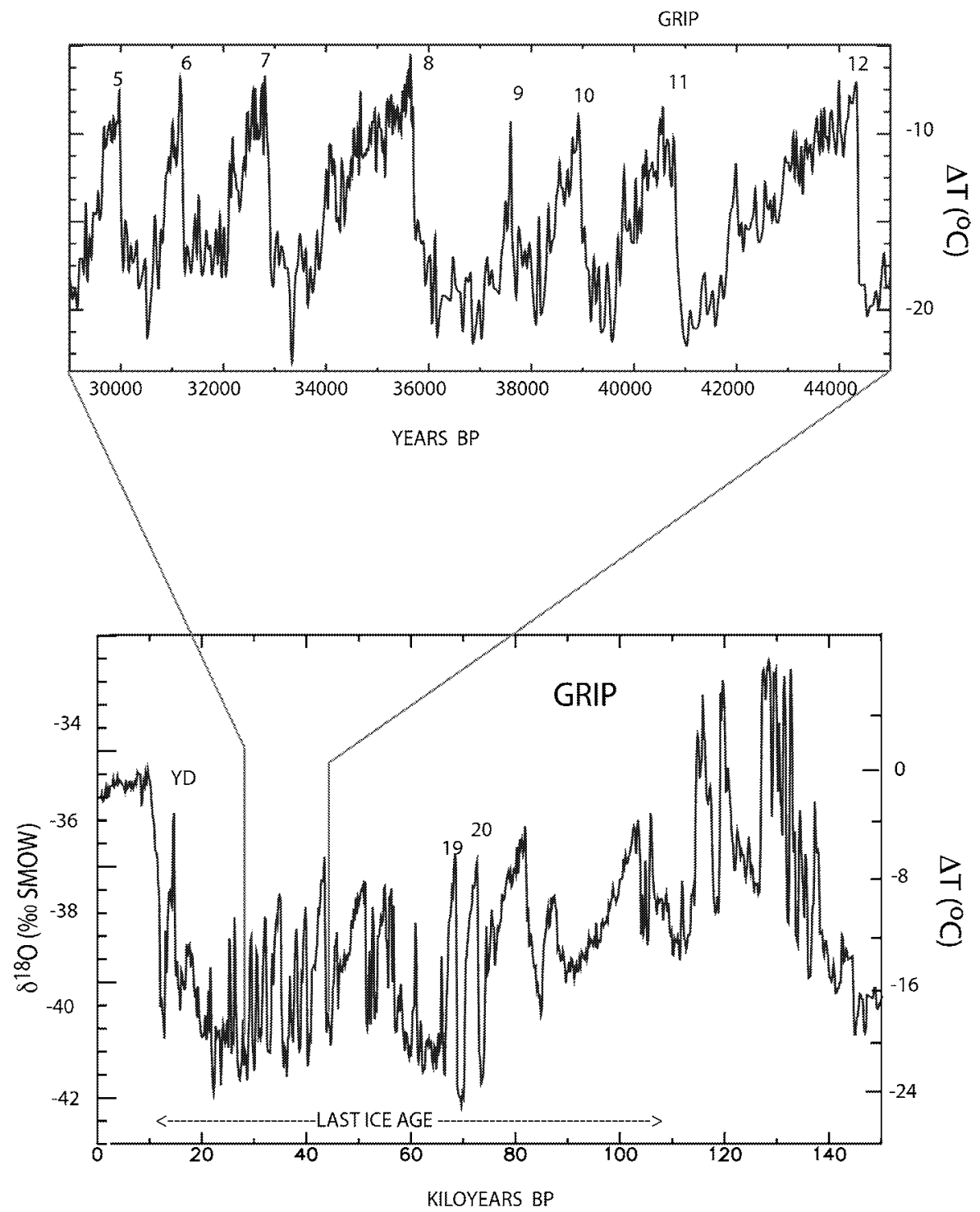

Figure $3 a$. Perhaps the most puzzling feature of recent paleoclimate records, highly relevant to understanding future global climate change, is the fast-warming/slow-cooling sequence found in the stable isotope fluctuations $\left(\delta^{18} \mathrm{O}\right)$ time series of Greenland's ice cores known as the Dansgaard-Oeschger (D/O) oscillations (Jouzel et al., 1994; Alley et al., 1999). The D/O typically show very sudden, 6-10 ${ }^{\circ} \mathrm{C}$ warming episodes lasting a few centuries or perhaps even a few decades, followed by millennia of relatively slow cooling. Remarkably, reconstructed sea surface temperatures (SST) in the tropical Atlantic (Figure 2b) mimic the D/O record in the $30 \mathrm{ka}$ to $60 \mathrm{ka}$ interval, and similar recordings are found in the subtropical Pacific and tropical Indian oceans. The longest period of the signal in the inset is a submultiple of the precession forcing and evidence of precession forcing exists elsewhere in the record (Rial, 2003). The ordinals near selected peaks correspond to numbered interstadials and YD is the Younger Dryas event (Dansgaard et al., 1993). 
a. STABLE, present-day climate

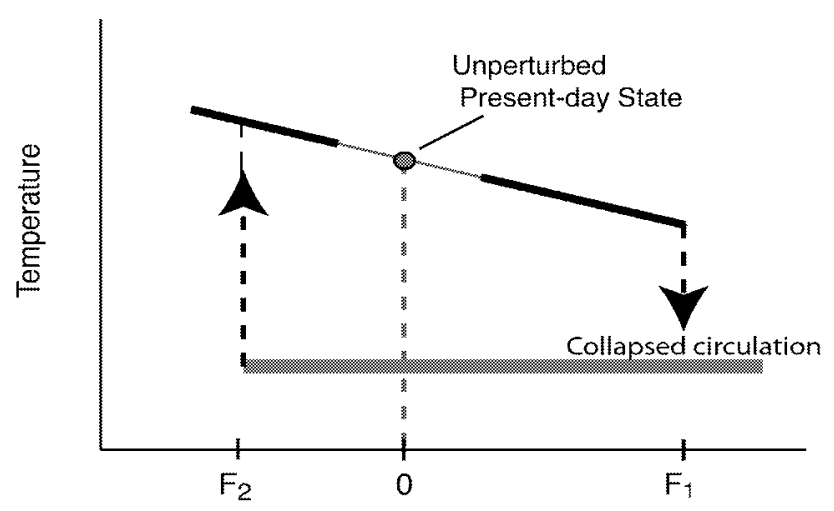

b. Last Glacial Maximum (LGM)



Figure 3b. Climate (temperature) stability as a function of freshwater input at high latitudes in the North Atlantic (Modified from Paillard, 2001).

extent by atmosphere-ocean interaction (Ganopolski et al., 1998; Braconnot et al., 1999). These lead to multiple equilibrium states (Claussen, 1997) with the possibility of abrupt changes when thresholds are crossed (Brovkin et al., 1998), as shown in Figure 4 (modified from Claussen et al. (1999) and DeMenocal et al. (2000)). This figure shows a model simulation of an abrupt decline in precipitation in the Sahara $\left(20^{\circ} \mathrm{N}-30^{\circ} \mathrm{N}\right.$ and $\left.15^{\circ} \mathrm{W}-50^{\circ} \mathrm{E}\right)$ around 5,500 years ago that is supported 

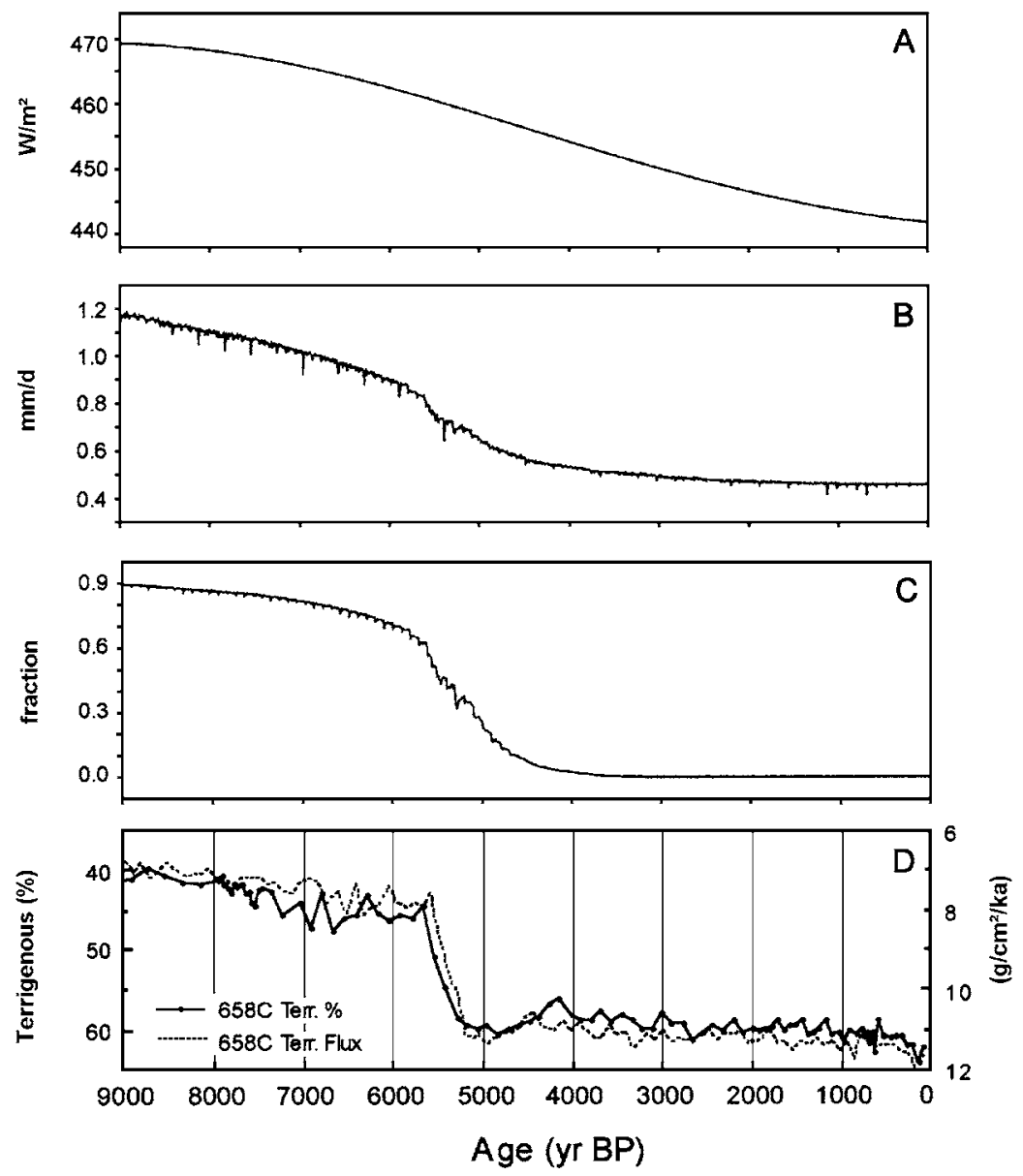

Figure 4. Simulation of transient development of precipitation (B), and vegetation fraction (C) as response to changes in insolation (A depicts insolation changes on average over the northern hemisphere during boreal summer). Results from Claussen et al. (1999) (B, C) are compared with data of terrigenous material and estimated flux of material in North Atlantic cores off the North African coast (D) by deMenocal et al. (2000). The figure is reproduced from Figure 2.8, in Kabat et al. (2003), with permission.

by observations from sediment cores off the North African coast. The rapid change contrasts markedly with the slow decrease in insolation.

\subsection{ABRUPT SHIFTS AND TRENDS OF HYDROCLIMATIC TIME SERIES}

Here we illustrate abrupt shifts and trends of hydroclimatic time series that occur at decadal time scales, as compared to hundreds and thousands of years in the previous examples. The effect of these changes on the environment and society are of current concern because of their occurrence during our lifetime. An example of complex time series with multidecadal trends are the annual flows of the Niger 
River at Koulikoro (Figure 5) and the outflows from the African equatorial lakes (Figure 6). As depicted in Figure 5, the Niger River series is characterized by a slow decaying autocorrelation function, reflecting a long 'memory', yet there are occasional large rapid shifts in the annual flows. Sveinsson et al. (2003) show that it is possible to simulate statistically similar time series patterns of streamflows that may occur in the future, and analyze the vulnerability of existing and projected water supply systems in this region. As evident in the time series outflows from the equatorial lakes measured at the Mongalla station for the period 1915-1983 (Figure 6), it is not necessary to employ any type of statistical analysis to recognize that something peculiar happened with the outflow time series around 1962. Some hydrologists have argued that such a sudden shift in the outflow may have been the result of the lakes' operation (e.g., Yevjevich, personal communication). However, others (e.g., Lamb, 1966, Figure 1) have documented that Lake Victoria levels also show a similar sudden shift during the same time period. Further analysis showed that the period 1961-1964 has been the wettest consecutive period for the entire historical precipitation record (Salas et al., 1981). Quite likely not only extreme precipitation over the equatorial lakes (e.g., the major water input to Lake Victoria is from precipitation over the lake itself) but also increases in the catchment runoff and decreases in the lake evaporation and land evaporation/transpiration (as a result of increased cloudiness of heavy rainy periods during the same time period) might have contributed to the occurrence of such significant and abrupt shifts in the Equatorial lakes levels and lake outflows.

\section{Nonlinear Irregular Oscillations and Chaos in Ocean-Atmosphere Interactions}

\subsection{NORTH ATLANTIC OSCILLATION AND EL NIÑO/SOUTHERN OSCILLATION}

The North Atlantic Oscillation (NAO) is a large-scale alternation of atmospheric pressure fields (i.e., atmospheric mass) with centers of action near the Icelandic Low and the Azores High. When sea-level pressure is lower than average in the Icelandic low pressure center, it is higher than average near the Azores, and vice-versa; which can be described as a sort of see-saw oscillating behavior of the system. Like ENSO (El Niño/Southern Oscillation), the NAO represents one of the most important modes of decadal-scale variability of the climate system, and accounts for up to $50 \%$ of sea-level pressure variability on both sides of the Atlantic (Hurrell, 1995). The NAO exerts a strong influence on precipitation and temperature on both the eastern third of North America and western half of Europe, particularly during winter months, and is responsible for many climatic anomalies (Beniston, 1997; Hurrell, 1995).

The North Atlantic Oscillation index is computed as a difference of sea-level pressure between the Azores (or Lisbon, Portugal) and Iceland. It is a measure 

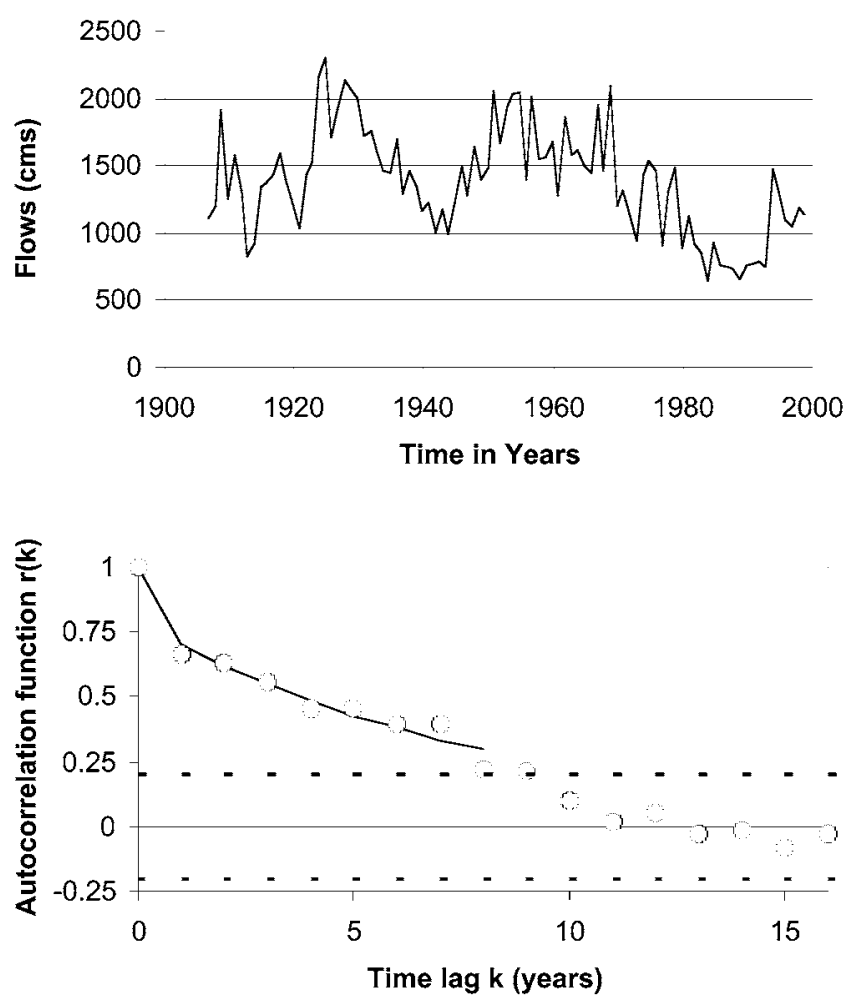

Figure 5. Time series of annual streamflows of the Niger River, Africa for the period 1907-1999 showing a complex pattern of high and low flows. The autocorrelation function shows the effect of long memory (modified from Sveinsson et al. 2003).

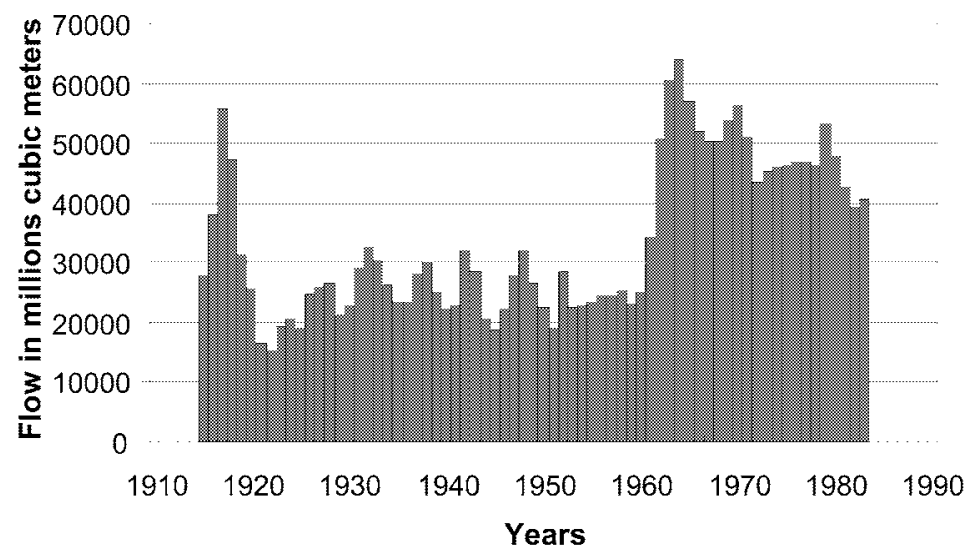

Figure 6. Time series of annual outflows from the African equatorial lakes measured at the Mongalla station for the period 1915-1983, showing an abrupt shift around 1961 and slow decaying downward trend (adapted from Salas et al. (1981). With permission). 
of the strength of zonal flows over the North Atlantic. A positive anomaly of the NAO index represents a warm phase of the oscillation, with drier and warmer than average conditions in the southern half of Europe. When the NAO index is strongly positive, there is a general reduction in atmospheric moisture at high elevations in the Alps (see e.g., Beniston and Jungo, 2002). Because of the highly positive nature of the NAO index in the latter part of the 20th century, it is speculated here that a significant part of the observed warming in the Alps results from shifts in temperature extremes induced by the behavior of the NAO. These changes are capable of having profound impacts on snow, hydrology, and mountain vegetation.

ENSO represents a nonlinear interplay of coupled ocean-atmosphere phenomena (e.g., Tziperman, 1994). El Niño is the warm phase of ENSO, whereby a weakening of the prevailing easterly trade winds in the equatorial Pacific allows the eastward propagation of warm surface water that normally accumulate to the west of the Pacific basin. Associated areas of deep convection 'migrate' with the propagation of the warm surface water, which are the principal energy source for convection. The area of anomalously warm surface water at the peak of an El Niño episode can reach 30 million $\mathrm{km}^{2}$, roughly 3 times the size of Canada, and consequently the sensible and latent heat exchange at the ocean-atmosphere interface is sufficient to perturb climatic patterns globally. This perturbation occurs in three simultaneous steps: vertical transfer of energy, heat and moisture through the deep convection, horizontal propagation through atmospheric flows at high elevations and, in time, an 'overflow' into the mid-latitude synoptic systems that can reinforce or weaken surface pressure patterns and deflect the jet streams from their usual trajectories. The cold phase of ENSO, commonly referred to as La Niña, occurs sometimes (but not always) at the end of an El Niño event. Anomalously cold waters invade the tropical Pacific region, and the strength of La Niña can in some instances reverse the previously discussed anomaly patterns, i.e., by reversing respective precipitation or drought patterns that occur during an El Niño event.

From a mechanistic point of view ENSO's irregular oscillations can be understood as those of a low-order chaotic system (Pacific ocean-atmosphere oscillator) driven by the seasonal cycle (Tziperman et al., 1994). Since chaotic systems are not totally unpredictable, at least not for the short time scale, it may eventually be possible to estimate a range of predictability for ENSO within which models can forecast with precision its short-term evolution.

\subsection{THE PACIFIC DECADAL OSCILLATION}

One close climate process to ENSO is the Pacific Decadal Oscillation (PDO), which is an atmosphere-ocean phenomenon associated with persistent, bimodal climate patterns in the North Pacific Ocean. The PDO is a numerical index based on sea surface temperatures (SSTs) in a specific region of the North Pacific (Mantua et al., 1997), which shows sudden shifting patterns with mean levels switching from positive to negative and vice versa in time scales of about 20-50 years (Salas 

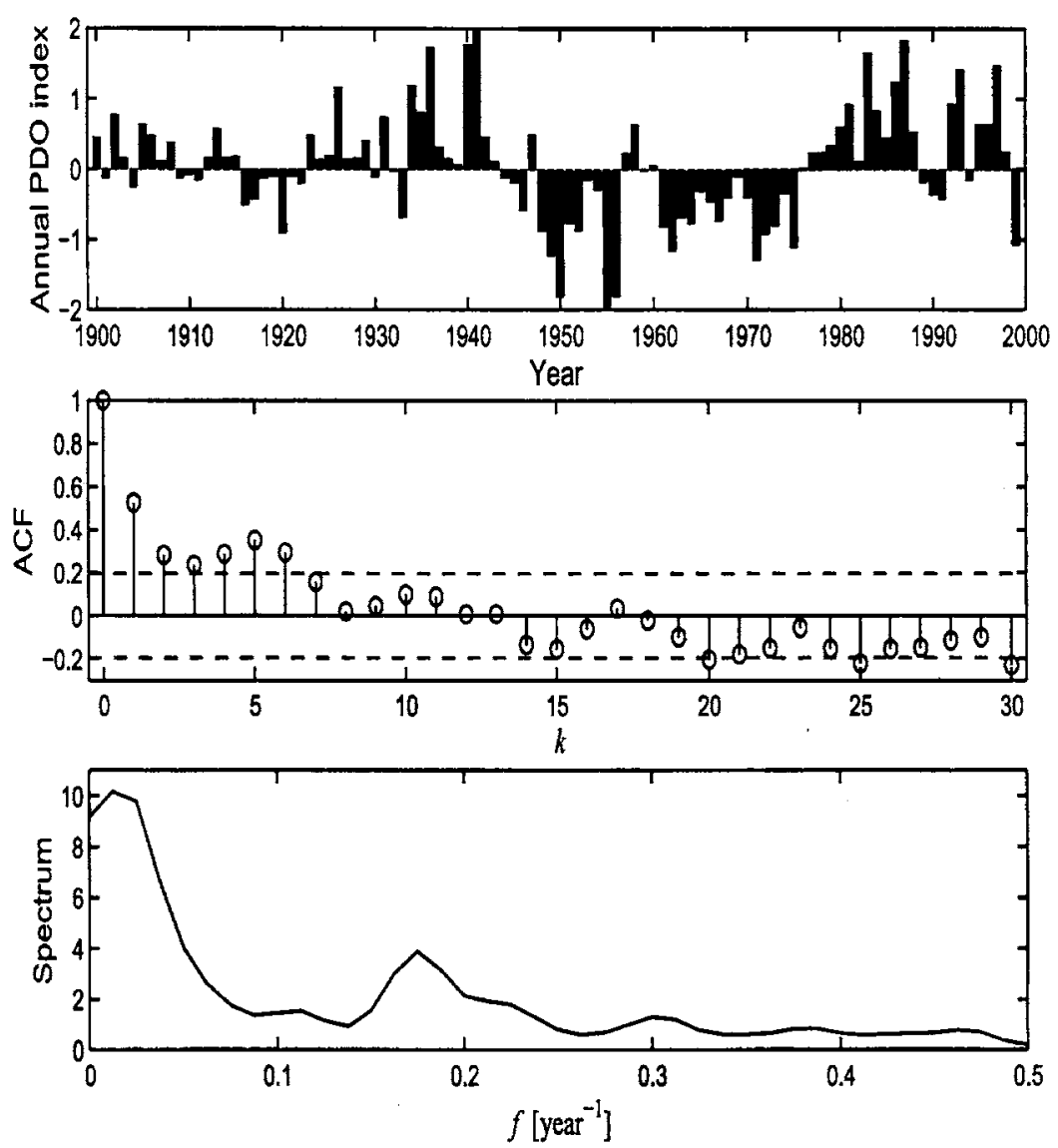

Figure 7. Autocorrelation function and power spectrum obtained for the time series of annual PDO indices for the period 1900-1999. The time series depicts abrupt shifts in addition to low frequency variations that appear non-stationary. Most of the power is at periods around 50 years. The spectrum also shows clear periodicities at around 5.7 years (adapted from Salas and Pielke (2002). With permission from John Wiley \& Sons, Inc.).

and Pielke, 2002). In Figure 7 the autocorrelation function and spectrum reflect the effect of a shifting low frequency pattern. Such shifting patterns illustrate the nonstationarity of the climate system, in that the assumption of the stability of socalled 'climate normals' does not adequately represent the real climate system. In comparison with ENSO, the physical dynamics associated with the PDO are not well understood, and the phase of the PDO is generally not predictable, although it is possible to create scenarios depicting similar shifting PDO patterns using stochastic methods (Sveinsson et al., 2003). 


\section{Nonlinearity and Feedbacks in the Carbon Cycle}

\subsection{ATMOSPHERE-CARBON CYCLE NONLINEAR FEEDBACKS}

The ocean, vegetation, and soil on the land are currently absorbing about half of the human emissions of atmospheric carbon dioxide $\left(\mathrm{CO}_{2}\right)$, which has significant implications for global climate change (Schimel et al., 2000). The processes involved in $\mathrm{CO}_{2}$ uptake by both land and ocean are known to be sensitive to the weather and atmospheric $\mathrm{CO}_{2}$ concentration, as well as other environmental factors, e.g., human perturbations to the nitrogen cycle (Vitousek et al., 1997). For example, the uptake of $\mathrm{CO}_{2}$ by the ocean depends upon the difference in the $\mathrm{CO}_{2}$ concentration across the ocean-air interface (which tends to increase as atmospheric $\mathrm{CO}_{2}$ rises), the solubility of $\mathrm{CO}_{2}$ in seawater (which reduces as temperature rises), and the transport of $\mathrm{CO}_{2}$ to depth in the ocean (which is suppressed by thermal stratification and also depends on the ocean circulation (Sarmiento et al., 1998)). Likewise, $\mathrm{CO}_{2}$ uptake by plants tends to increase with increasing $\mathrm{CO}_{2}$ (depending upon the availability of nutrients, water, temperature, and other variables, such as ozone concentration) (Körner, 2000), but the breakdown of soil organic matter (SOM) is a highly nonlinear process, characterized by a number of nonlinear feedback loops involving plants, microbes, SOM, and nutrient availability. Cheng (1999) characterized one such loop operating in forests as follows: (i) increasing $\mathrm{CO}_{2}$ uptake by plants leads to an increase in carbon inputs to the rhizosphere (plant roots, soil microorganisms, soil); (ii) increased soil carbon may or may not stimulate increases in microbial respiration; (iii) altered rhizosphere respiration may either increase or decrease SOM decomposition; (iv) changes in SOM decomposition cause changes in soil nutrient mineralization and immobilization; (v) changes in soil nutrient dynamics affect tree growth; and (vi) changes in tree growth have key implications for global carbon sequestering, and hence, climate change. Supporting this, Gill et al. (2002) reported that mineralization rates in soils of a Texas grassland decreased nonlinearly with increasing $\mathrm{CO}_{2}$, and speculated that such decreases in nitrogen availability will likely have a detrimental effect on long-term plant productivity and, ultimately, on ecosystem carbon storage.

\subsection{LAND-USE/VEGETATION FEEDBACKS ON THE REGIONAL SCALE}

Eastman et al. (2001a,b) have shown that land-use change, grazing, and increased carbon dioxide can significantly alter the regional climate system in the central Great Plains of the United States. Figure 8 shows these effects on maximum and minimum temperature, rainfall, and above ground biomass growth during a growing season in this region. For example, the effects of enhanced atmospheric concentrations of $\mathrm{CO}_{2}$ on plant growth on a seasonal time scale are shown to amplify the radiative effect of enhanced atmospheric $\mathrm{CO}_{2}$ on the region. The nonlinear effect of vegetation-atmospheric feedback on this scale results in a complex spatial and temporal pattern of response. Not only is there a teleconnection of 

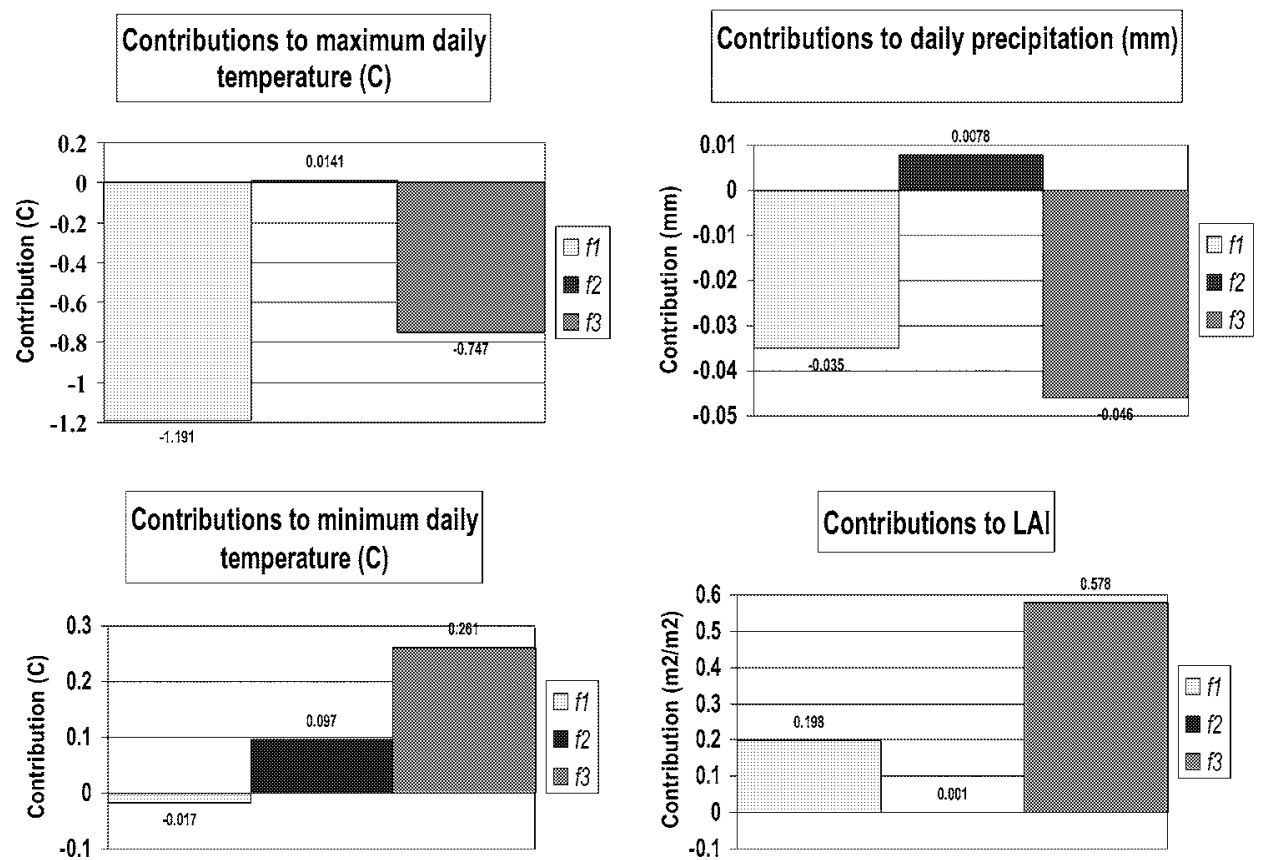

Figure 8. RAMS/GEMTM nonlinear coupled model results - the seasonal domain-averaged (central Great Plains) for 210 days during the growing season, contributions to maximum daily temperature, minimum daily temperature, precipitation, and leaf area index (LAI) due to: $f 1=$ natural vegetation, $f 2=2 \times \mathrm{CO}_{2}$ radiation, and $f 3=2 \times \mathrm{CO}_{2}$ biology (adapted from Eastman et al. (2001), with permission from Blackwell Publishing).

atmospheric conditions to locations distant from where the land feedback occurs, but the landscape at distant locations itself is influenced by the altered weather. In manipulative vegetation experiments where carbon dioxide concentrations are arbitrarily increased, for example, this nonlinear feedback between the atmosphere and land surface is missed since there is no feedback to the regional weather (with greater vegetation cover resulting in greater summer rainfall and cooler maximum temperatures.)

\section{3. 'SATURATION' OF THE ATMOSPHERIC OXIDATION PROCESS}

The removal of a large number of greenhouse and polluting gases from the atmosphere (including all hydrocarbons, carbon monoxide (CO), nitrogen oxides $\left(\mathrm{NO}_{x}\right)$, sulfur oxides $\left(\mathrm{SO}_{x}\right)$ ) is accomplished through their reaction in the lower atmosphere with the hydroxyl free radical $(\mathrm{OH})$. This radical is produced by processes involving nitrogen oxides, ozone, water vapor and short-wavelength ultraviolet radiation, and removed by reactions with the aforementioned gases. All else being equal, lowering emissions of nitrogen oxides and/or increasing emissions of carbon monoxide and methane, could erode $\mathrm{OH}$ levels, and therefore 
increase the lifetimes of the above greenhouse gases (Thompson and Cicerone, 1986; Prinn et al., 2001). The atmospheric concentration of methane and other greenhouse gases becomes a nonlinear function of emission rate since the reaction process itself is dependent on their atmospheric concentrations, which in turn is dependent on the emissions. Such combinations of emission changes therefore constitute a positive feedback on climate change.

\subsection{METHANE POSITIVE FEEDBACK PROCESSES}

Methane is the third most important greenhouse gas (after water vapor and carbon dioxide). Two of its sources, or potential sources, exhibit nonlinear behavior. Methanogens in the wetlands become increasingly active with warming above the freezing point, while methane clathrate hydrates in submarine and subtundral deposits become methane sources above their known stability temperatures (Prinn et al., 1999; Buffett, 2000). Atmospheric methane is already a significant consumer of the very chemical (hydroxyl radical $\mathrm{OH}$ ) which removes it. All else being equal, increased methane emissions from wetlands and new emissions from clathrates will therefore lower $\mathrm{OH}$ and increase the lifetime (and hence greenhouse forcing) of methane above its current values (Prather, 1996). Thus, for methane, the two sources above and the $\mathrm{OH}$ sink behave in a way that can constitute a significant positive feedback on warming.

\section{Consequences of a Complex, Nonlinear Earth System}

In spite of the necessarily incomplete set of examples discussed above we hope to have contributed to convey some of the challenges that researchers face in a field where the dynamics are still being understood. The examples we chose illustrate the existence of a wide diversity of nonlinear interactions that results in the recognizable variability of climatic processes, but we have only touched the surface. If spatial domain and long-distance interactions are included, there is much more to investigate. For example, large-scale atmospheric circulation patterns exert a major influence on local weather. Conversely, thunderstorm development exemplifies how small-scale climate processes can upscale to affect large-scale atmospheric circulations at long distances from the source of the disturbance (i.e., teleconnections). Another example is the land-use change in the tropics, which nonlinearly influences thunderstorm patterns that propagate worldwide (Chase et al., 2000; Zhao et al., 2000; Pielke, 2001b; Pielke et al., 2002).

On the other hand, our examples lead to an inevitable conclusion: since the climate system is complex, occasionally chaotic, dominated by abrupt changes and driven by competing feedbacks with largely unknown thresholds, climate prediction is difficult, if not impracticable. Recall for instance the abrupt $\mathrm{D} / \mathrm{O}$ warming events (Figure 3a) of the last ice age, which indicate regional warming of over $10{ }^{\circ} \mathrm{C}$ in Greenland (about $4{ }^{\circ} \mathrm{C}$ at the latitude of Bermuda). These natural warming 
events were far stronger - and faster - than anything current GCM work predicts for the next few centuries. Thus, a reasonable question to ask is: Could present global warming be just the beginning of one of those natural, abrupt warming episodes, perhaps exacerbated (or triggered) by anthropogenic $\mathrm{CO}_{2}$ emissions? Since there is no reliable mechanism that explains or predicts the $\mathrm{D} / \mathrm{O}$, it is not clear whether the warming events occur only during an ice age or can also occur during an interglacial, such as the present. Other limitations in predictive skill for a variety of environmental issues have been recently discussed in Sarewitz et al. (2000), so prediction of future environmental change seems daunting, at least at present.

Hence, it appears that one should not rely on prediction as the primary policy approach to assess the potential impact of future regional and global climate change. We argue instead that integrated assessments within the framework of vulnerability (IAV) offer the best solution, whereby risk assessment and disaster prevention become the alternative to prediction.

In the Working Group II Report of the IPCC, vulnerability is defined as 'the degree to which a system is susceptible to, or unable to cope with, adverse effects of climate change, including climate variability and extremes' (McCarthy, 2001). The vulnerability of a particular system is, of course, a function of both the magnitude and rate of climate change as well as the current state of the system (i.e., its adaptive capacity). Using this methodology, 'impact models' are applied to assess the spectrum of potential changes in environmental forcings that result in deleterious effects on a particular system. This quantification of the vulnerability of a system can provide insight into the relative importance of climate, with respect to other environmental influences. For example, Vörösmarty et al. (2000) use the IAV approach to demonstrate that population growth is a much greater threat to potable water supplies than the IPCC-predicted climate change. Other examples are reported in Kabat et al. (2003), including the mathematical formalism to investigate vulnerability.

The value of a vulnerability assessment is that the approach focuses on the integrated effect of the spectrum of forcings and feedbacks on a system (e.g water resources). Instead of attempting to predict the future state of a system, the risk to a resource from all environmental (or other) threats is determined including the presence of thresholds and their resiliency. Prevention substitutes prediction.

Global and regional projections based on models, the paleoclimatic and paleoenvironmental records, the historical record, and worst-case perturbations of the historical record can be used to estimate which vulnerabilities have a reasonable likelihood of occurring and eventually how to cope with them. Examples of the application of the vulnerability approach, which can be used to assess the resilience and sensitivity of different countries and cultures to environmental disturbance, include 'what if' scenarios such as:

- The 'dust bowl' years of the 1930s were to occur again in the United States;

- The 'Little Ice Age' were to reoccur in Western Europe; 
- An abrupt warming on the scale of the D/O (Figure 3a) was to occur; or

- Major volcanic eruptions similar to Tambora in 1815 were to take place?

The consequences (and, when possible, the probabilities) of these events need to be assessed in the context of current socioeconomic and cultural conditions.

\section{Recommended Research Areas}

We have provided examples to illustrate that inputs and outputs within the Earth's climate system are not proportionate, that change is often episodic and abrupt - not gradual and continuous - and multiple equilibria are the norm, not the exception - consistent with the presumed nonlinear nature of Earth's climate system. Actually, that the Earth's climate system responds nonlinearly to (internal or external) forcing seems widely accepted. However, what sort of nonlinearities are there, how strong, and whether driven by astronomical forcing, by internal feedbacks, or by both is far less clear, and only poorly understood. Given this, it is imperative for the research community to adopt a research strategy that embraces the nonlinear climate paradigm by, for instance, learning to identify the symptoms of nonlinearity in the data, and to use the modern theoretical and practical means (models, data processing) of diagnosing major climatic threats to society.

Therefore, we have agreed on a list of desirable research strategies - some of which are specific, employing integrated assessments within the framework of a vulnerability approach, and some of which are general. The list is not intended to be exhaustive but hopefully illustrative of the many challenges (and opportunities) facing the Earth's climate system research community. Accordingly, we recommend to

- Explore the limits to climate predictability and search for switches and choke points (or hot spots) of environmental change and variability.

- Construct models to explain the nonlinear response of the climate system to changes in insolation forcing due to orbital parameter changes, an objective best approached from the paleoclimate perspective.

- Improve our vision of the climate's future through a better understanding of its history. Paleoclimate and hydroclimate records exhibit abrupt changes in the form of rapid warming events, the irregular oscillations of ENSO, catastrophic floods, sustained droughts, and many other nonlinear response characteristics. Extracting, identifying, categorizing, modeling and understanding these nonlinearities will greatly help our ability to understand the present and future state of the climate.

- Develop GCMs coupled to low-dimensional energy balance ice sheet/lithosphere hybrid models (e.g., Deconto and Pollard, 2003) that can simulate the interaction between hydrosphere, atmosphere and land over a wide range of spatial (continental to global) and temporal (centennial, millennia) scales. 
- Understand the global connectivity and variability of ocean-atmosphere coupled phenomena, such as the North Pacific Oscillation (NPO), the Pacific Decadal Oscillation (PDO), the Arctic Oscillation (AO), the North Atlantic Oscillation (NAO), and the El Niño/Southern Oscillation (ENSO).

- Promote research to improve techniques that measure directly or indirectly the spectral variability of the Sun's irradiance output at decadal and millennial scales.

- Understand the physics of the ocean thermohaline circulation (THC), whose collapse may be one important cause of major climatic change in Western Europe and North America (Rahmstorf, 2000).

- Perform sensitivity experiments with global climate models to evaluate the response of the climate system to biospheric interactions (including vegetation dynamics, and the effect associated with the anthropogenic input of carbon dioxide and nitrogen compounds), the microphysical effects on clouds and precipitation due to anthropogenic aerosol emissions, and land-use change including fragmentation of ecosystems. Existing experiments to explore these effects include Cox et al. (2000), Eastman et al. (2001b), and Pielke (2001a,b).

- Investigate the benefits and risks of large-scale deliberate human intervention in the climate system. For example, carbon sequestration, associated with land-management practices could be a strategy to remove $\mathrm{CO}_{2}$ from the atmosphere. This should include the concurrent effect on water vapor fluxes into the atmosphere and the net irradiance received at the Earth's surface (e.g., Betts, 2000; Claussen, 2001; Pielke, 2001c). Another example is the effect of the construction of large-scale water systems and the control of large lakes such as Lake Victoria and the Great Lakes on regional climate systems.

- Identify locations or regions that are particularly sensitive to or easily impacted by the planetary climate system. The Amazon rain forest and its fluvial regime (Cox et al., 2000; Werth and Avissar, 2002), Southeast Asia (Chase et al., 2000), the North Atlantic Ocean (Rahmstorf, 2000), the Arctic Ocean (Foley et al., 1994), the boreal forest (Bonan et al., 1992), and the Nile River system are examples of such sensitive locations.

- Investigate in increasing detail, nonlinear interactions involving changes in biospheric emissions of chemically and radiatively important trace gases, changes in atmospheric chemistry affecting the lifetimes of these gases, and resultant changes in radiative forcing. Examples of such investigations using simplified models include Homes and Ellis (1999) and Prinn et al. (1999).

To conclude, we recommend the development of new educational initiatives on environmental/climate science. The complexity of the climate system, its myriad of parts, interactions, feedbacks and unsolved mysteries needs researchers able to transcend their own specialties, jump over and build bridges across artificial disciplinary boundaries. Hence, a fundamental requirement for the future environmentalist/climatologist is a firm grasp of the mathematics and physics of 
nonlinearity and of the methods and goals of interdisciplinary climate science. We enthusiastically endorse John Lawton's (2001) call for establishing specific programs on 'Earth System Science' (ESS) at various institutions and universities, in order to provide upcoming generations of scientists with insight into the complexity, the interdisciplinary nature and the crucial importance of these themes for the future of humanity. The greatest challenge is to build a strong research infrastructure that defines ESS, and as Lawton notes, the greatest barrier at present is the lack of organizations ready to nurture this new discipline.

\section{Acknowledgements}

This paper resulted from a Workshop entitled 'Nonlinear Responses to Global Environmental Change: Critical Thresholds and Feedbacks - IGBP Nonlinear Initiative', organized by the International Biosphere-Geosphere Program (IGBP) May 26-27th, 2001, Duke University, Durham, North Carolina. This paper contributes to the new IGBP Nonlinear Initiative and to the efforts of individual core projects on this topic including BAHC, GCTE, PAGES, and GAIM. Support for this research includes that obtained from USGS Grant \#99CRAG005 and SA 9005CS0014. JAR was partially supported by NSF grant \#ATM0241274 (Paleoclimate program). We appreciate the detailed comments of an anonymous reviewer, the editing skills of Dallas J. Staley and the incisive comments of Maya Elkibbi.

\section{References}

Alley, R. B., Clark, P. U., Keiwin, L. D., and Webb, R. S.: 1999, 'Making Sense of Millennial Scale Climate Change', in Clark, P. U., Webb, R. S., and Keiwin, L. D. (eds.), Mechanisms of Global Climate Change at Millennial Time Scales, Amer. Geophys. Union, Geophys. Monogr. 112, 385394.

Alley, R. B., Marotzke, J., Nordhaus, W. D., Overpeck, J. T., Peteet, D. M., Pielke Jr., R. A., PierRehumbert, R. T., Rhines, P. B., Stocker, T. F., Talley, L. D., and Wallace, J. M.: 2003, 'Abrupt Climate Change', Science 299, 2005-2010.

Aspen Global Change Institute: 1998, 'Elements of Change 1997: Session One: Scaling from SiteSpecific Observations to Global Model Grids'.

Beniston, M.: 1997, 'Variations of Snow Depth and Duration in the Swiss Alps over the Last 50 Years: Links to Changes in Large-Scale Climatic Forcings', Clim. Change 36, 281-300.

Beniston, M. and Jungo, P.: 2002, 'Shifts in the Distributions of Pressure, Temperature and Moisture and Changes in the Typical Weather Patterns in the Alpine Region in Response to the Behavior of the North Atlantic Oscillation', Theor. Appl. Climatol. 71, $29-42$.

Berger, A. and Loutre, M. F.: 1991, 'Insolation Values for the Climate of the Last 10 Million of Years', Quat. Sci. Rev. 10 (4), 297-317.

Betts, R. A.: 2000, 'Offset of the Potential Carbon Sink from Boreal Forestation by Decreases in Albedo', Nature 408, 187-190.

Bonan, G. B., Pollard, D., and Thompson, S. L.: 1992, 'Effects of Boreal Forest Vegetation on Global Climate', Nature 359, 716-718. 
Braconnot, P., Joussaume, S., Marti, O., and de Noblet-Ducoudre, N.: 1999, 'Synergistic Feedbacks from Ocean and Vegetation on the African Monsoon Response to Mid-Holocene Insolation', Geophys. Res. Lett. 26, 2481-2484.

Brovkin, V., Claussen, M., Petoukhov, V., and Ganopolski, A.: 1998, 'On the Stability of the Atmosphere-Vegetation System in the Sahara/Sahel Region', J. Geophys. Res. 103, 3161331624.

Buffett, B. A.: 2000, 'Clathrate Hydrates', Ann. Rev. Earth Planet. Sci. 28, 477-508.

Chase, T. N., Pielke, R. A., Kittel, T. G. F., Nemani, R. R., and Running, S. W.: 2000, 'Simulated Impacts of Historical Land Cover Changes on Global Climate', Clim. Dyn. 16, 93-105.

Cherney, J. and Stone, P. H.:1975, 'Drought in the Sahara: A Biogeophysical Feedback Mechanism', Science 187, 434-435.

Cheng, W. X.: 1999, 'Rhizosphere Feedbacks in Elevated $\mathrm{CO}_{2}$ ', Tree Physiol. 19, 313-320.

Clark, P. U., Alley, R. B., and Pollard, D.: 1999, 'Northern Hemisphere Ice Sheet Influences on Global Climate Change', Science 286, 1104-1111.

Clark, P. U., Pisias, N. G., Stocker, T. F., and Weaver, A. J.: 2002, 'The Role of the Thermohaline Circulation in Abrupt Climate Change, Nature 415, 863-869.

Claussen, M.: 1997, 'Modelling Biogeophysical Feedback in the African and Indian Monsoon Region', Clim. Dyn. 13, 247-257.

Claussen, M.: 2001, 'Earth System Models', in Ehlers, E. and Krafft, T. (eds.), Understanding the Earth System: Compartments, Processes and Interactions, Springer-Verlag, Heidelberg, pp. 145162.

Claussen, M. and Gayler, V.: 1997, 'The Greening of Sahara during the Mid-Holocene: Results of an Interactive Atmosphere-Biome Model', Global Ecol. Biogeog. Lett. 6, 369-377.

Claussen, M., Kubatzki, C., Brovkin, V., Ganopolski, A., Hoelzmann, P., and Pachur, H. J.: 1999, 'Simulation of an Abrupt Change in Saharan Vegetation at the End of the Mid-Holocene', Geophys. Res. Lett. 26, 2037-2040.

Claussen, M., Mysak, L. A., Weaver, A. J., Crucifix, M., Fichefet, T., Loutre, M.-F., Weber, S. L., Alcamo, J., Alexeev, V. A., Berger, A., Calov, R., Ganopolski, A., Goosse, H., Lohmann, G., Lunkeit, F., Mokhov, I. I., Petoukhov, V., Stone, P., and Wang, Z.: 2002, 'Earth Systems Models of Intermediate Complexity: Closing the Gap in the Spectrum of Climate System Models', Clim. Dyn. 18, 579-586.

Cowan, G. A., Pines, D., and Meltzer, D.: 1999, Complexity, Metaphors, Models and Reality, Perseus Books, Santa Fe Institute.

Cox, P. M., Betts, R. A., Jones, C. D., Spall, S. A., and Totterdell, I. J.: 2000, 'Acceleration of Global Warming Due to Carbon-Cycle Feedbacks in a Coupled Climate Model', Nature 408, 184-187.

Cronin, T. M. (1999): Principles of Paleoclimatology, Columbia U. Press, New York.

DeConto, R. and Pollard, D.: 2003, 'Rapid Cenozoic Glaciation of Antarctica Induced by Declining Atmospheric $\mathrm{CO}_{2}$ ', Nature 421, 245-249. deMenocal, P. B., Ortiz, J., Guilderson, T., Adkins, J., Sarnthein, M., Baker, L., and Yarusinsky, M.: 2000, 'Abrupt Onset and Termination of the African Humid Period: Rapid Climate Response to Gradual Insolation Forcing', Quat. Sci. Rev. 19, 347-361. de Noblet-Ducoudre, N. and Claussen, M.: 2001, 'Mid-Holocene Greening of the Sahara: First Results of the GAIM 6000 Year BP Experiment with Two Asynchronously Coupled Atmosphere/Biome Models', Clim. Dyn. 16, 643-659.

Doherty, R., Kutzbach, J., Foley, J., and Pollard, D.: 2000, 'Fully Coupled Climate/Dynamical Vegetation Model Simulations over Northern Africa during the Mid-Holocene', Clim. Dyn. 16, 561-573.

Eastman, J. L., Coughenour, M. B., and Pielke, R. A. Sr.: 2001a, 'The Effects of $\mathrm{CO}_{2}$ and Landscape Change Using a Coupled Plant and Meteorological Model', Global Change Biol. 7, 797-815.

Eastman, J. L., Coughenour, M. B., and Pielke, R. A. Sr.: 2001b, 'Does Grazing Affect Regional Climate', J. Hydrometeor. 2, 243-253. 
Foley, J., Kutzbach, J. E., Coe, M. T., and Levis, S.: 1994, 'Feedbacks between Climate and Boreal Forests during the Holocene Epoch', Nature 371, 52-54.

Gallagher, R. and Appenzeller, T.: 1999, 'Beyond Reductionism: Introduction to Special Section on Complex Systems', Science 284, 79-109.

Ganopolski, A., Kubatzki, C., Claussen, M., Brovkin, V., and Petoukhov, V.: 1998, 'The Influence of Vegetation-Atmosphere-Ocean Interaction on Climate during the Mid-Holocene', Science 280, 1916-1919.

Ganopolski, A. and Rahmstorf, S.: 2001, 'Rapid Changes of Glacial Climate Simulated in a Coupled Climate Model', Nature 409, 153-158.

Ghil, M.: 1994, 'Cryothermodyamics: The Chaotic Dynamics of Paleoclimate', Physica D 77, 130159.

Gill, R. A., Polley, H. W., Johnson, L. J., Maherali, H., and Jackson, R.: 2002, 'Nonlinear Grasslands Responses to Past and Future Atmospheric $\mathrm{CO}_{2}$ ', Nature 417, 279-282.

Goldenfeld, N. and Kadanoff, L. P.: 1999, 'Simple Lessons from Complexity', Science 284, 87-89.

GRIP Project Members: 1993, 'Climate Instability during the Last Interglacial Period Recorded in the GRIP Ice Core', Nature 364, 203-207.

Homes, K. J. and Ellisa, J. H.: 1999, 'An Integrated Assessment Modeling Framework for Assessing Primary and Secondary Impacts from Carbon Dioxide Stabilization Scenarios', Environ. Model. Assess. 4, 45-63.

Hurrell, J. W.: 1995, 'Decadal Trends in the North Atlantic Oscillation Regional Temperatures and Precipitation', Science 269, 676-679

Imbrie, J., Berger, A., Boyle, E. A., Clemens, S. C., Duffy, A., Howard, W. R., Kukla, G., Kutzbach, J., Martinson, D. G., McIntyre, A., Mix, A. C., Molfino, B., Morley, J. J., Peterson, L. C., Pisias, N. G., Prell, W. L., Raymo, M. E., Shackleton, N. J., and Toggweiler, J. R.: 1993, 'On the Structure and Origin of Major Glaciation Cycles 2. The 100,000-Year Cycle', Paleoceanography $8(6), 699-735$.

Joussaume, S., Taylor, K. E., Braconnot, P., Mitchell, J. F. B., Kutzbach, J. E., Harrison, S. P., Prentice, I. C., Broccoli, A. J., Abe-Ouchi, A., Bartlein, P. J., Bonfiels, C., Dong, B., Guiot, J., Herterich, K., Hewit, C. D., Jolly, D., Kim, J. W., Kislov, A., Kitoh, A., Loutre, M. F., Masson, V., McAvaney, B., McFarlane, N., deNoblet, N., Peltier, W. R., Peterschmitt, J. Y., Pollard, D., Rind, D., Royer, J. F., Schlesinger, M. E., Syktus, J., Thompson, S., Valdes, P., Vettoretti, G., Webb, R. S., and Wyputta, U.: 1999, 'Monsoon Changes for 6000 Years Ago: Results of 18 Simulations from the Paleoclimate Modeling Intercomparison Project (PMIP)', Geophys. Res. Lett. 26, 859-862.

Kabat, P., Claussen, M., Dirmeyer, P. A., Gash, J. H. C., Bravo de Guenni, L., Meybeck, M., Pielke Sr., R. A., Vörösmarty, C. J., Hutjes, R. W. A., and Lütkemeier, S. (eds.): 2003, Vegetation, Water, Humans and the Climate: A New Perspective on an Interactive System, Springer, Berlin, Heidelberg, New York, approx. 550 pp., in press.

Kaplan, D. and Glass, L.: 1995, Understanding Nonlinear Dynamics, Springer-Verlag, New York.

Kim, Y. C. and Powers, E. J.: 1978, 'Digital Bispectral Analysis of Self-Excited Fluctuation Spectra', Phys. Fluids 21, 1452-1453.

Körner, C.: 2000, 'Biosphere Responses to $\mathrm{CO}_{2}$ Enrichment', Ecol. Appl. 10, 1590-1619.

Kutzbach, J. E. and Guetter, P. J.: 1986, 'The Influence of Changing Orbital Parameters and Surface Boundary Conditions on Climate Simulations for the Past 18,000 Years', J. Atmos. Sci. 43, 17261759.

Lawton, J. H.: 2001, 'Earth System Science', Science 292, 1965.

Lamb, H. H.: 1966, 'Climate in the 1960s', Geogr. J. 132, 183-212.

Lorenz, E. N.: 1963, 'Deterministic Nonperiodic Flow', J. Atmos. Sci. 20, 130-141

Mantua, N. J., Hare, S. R., Zhang, Y., Wallace, J. M., and Francis, R. C.: 1997, ‘A Pacific Interdecadal Climate Oscillation with Impacts on Salmon Production', Bull. Amer. Meteorol. Soc. 78, 10691079. 
May, R. M.: 1976, 'Simple Mathematical Models with Very Complicated Dynamical Behavior', Nature 261, 459-467.

McCarthy, J. J., Canziani, O. F., Leary, N. A., Dokken, D. J., and White, K. S. (eds.): 2001, Climate Change 2001: Impacts, Adaptation and Vulnerability, Contribution of Working Group II to the Third Assessment Report of the Intergovernmental Panel on Climate Change (IPCC), Cambridge University Press, Cambridge.

Mudelsee, M. and Schultz, M.: 1997, 'The Mid-Pleistocene Climate Transition: Onset of the $100 \mathrm{ka}$ Cycle Lags Ice Volume Build-up by 280 ka', Earth Planet. Sci. Lett. 151, 117-123.

Nobes, D. C., Bloomer, S. F., Mienert, J., and Westall, F.: 1991, 'Milankovitch Cycles and Nonlinear Response in the Quaternary Record in the Atlantic Sector of the South Oceans', Proceedings ODP Scientific Results 114, 551-576.

Paillard, D.: 2001, 'Glacial Hiccups', Nature 409, 147-148.

Petit, J. R., Jouzel, J., Raynaud, D., and Barkov, N. I.: 1999, 'Climate and Atmospheric History of the Past 420,000 Years from the Vostok Ice Core, Antarctica', Nature 399, 429-436.

Pielke Sr., R. A.: 2001a, 'Earth System Modeling - An Integrated Assessment Tool for Environmental Studies', in Matsuno, T. and Kida, H. (eds.), Present and Future of Modeling Global Environmental Change: Toward Integrated Modeling, Terra Scientific Publishing Company, Tokyo, Japan, pp. 311-337.

Pielke Sr., R. A.: 2001b, 'Influence of the Spatial Distribution of Vegetation and Soils on the Prediction of Cumulus Convective Rainfall', Rev. Geophys. 39, 151-177.

Pielke Sr., R. A.: 2001c, 'Carbon Sequestration: The Need for an Integrated Climate System Approach', Bull. Amer. Meteor. Soc. 82, 2021.

Pielke Sr., R. A., Marland, G., Betts, R. A., Chase, T. N., Eastman, J. L., Niles, J. O., Niyogi, D., and Running, S.: 2002, 'The Influence of Land-Use Change and Landscape Dynamics on the Climate System-Relevance to Climate Change Policy beyond the Radiative Effect of Greenhouse Gases', Phil. Trans. A. Special Theme Issue 360, 1705-1719.

Pisias, N. G., Mix, A. C., and Zahn, R.: 1990, 'Nonlinear Response in the Global Climate System: Evidence from Benthic Oxygen Isotopic Record in Core RC13-110', Paleoceanography 5 (2), $147-160$.

Prentice, I. C., Jolly, D., and BIOME 6000 members: 2000, 'Mid-Holocene and Glacial-Maximum Vegetation Geography of the Northern Continents and Africa', J. Biogeogr. 27, 507-519.

Prather, M. J.: 1996, 'Natural Modes and Time Scales in Atmospheric Chemistry: Theory, GWPs for $\mathrm{CH}_{4}$ and $\mathrm{CO}$, and Runaway Growth', Geophys. Res. Lett. 23, 2597-2600.

Prinn, R. G., Jacoby, H. D., Sokolov, A., Wang, C., Xiao, X., Yang, Z., Eckaus, R. S., Stone, P. H., Ellerman, A. D., Melillo, J. M., Fitzmaurice, J., Kicklighter, D. W., Holian, G. L., and Liu, Y.: 1999, 'Integrated Global System Model for Climate Policy Assessment: Feedbacks and Sensitivity Studies', Clim. Change 41, 469-546.

Prinn, R. G., Huang, J., Weiss, R. F., Cunnold, D. M., Fraser, P. J., Simmonds, P. G., Harth, C., Salameh, P., O’Doherty, S., Wang, R. H. J., Porter, L., and Miller, B. R.: 2001, 'Evidence for Substantial Variations of Atmospheric Hydroxyl Radicals in the Last Two Decades', Science 292, 1882-1888.

Rahmstorf, S.: 2000, 'The Thermohaline Ocean Circulation: A System with Dangerous Thresholds?', Clim. Change 46, 247-256.

Rahmstorf, S.: 2001, 'Abrupt Climate Change', in Steele, J., Thorpe, S., and Turekian, K. (eds.), Encyclopedia of Ocean Sciences, Academic Press, London, pp. 1-6.

Raymo, M. E.: 1997, 'The Timing of Major Climate Terminations', Paleoceanography 12, 577-585.

Rial, J. A.: 1999, 'Pacemaking the Ice Ages by Frequency Modulation of Earth's Orbital Eccentricity', Science 285, 564-568.

Rial, J. A.: 2003, 'Abrupt Climate Change: Chaos and Order at Orbital and Millennial Scales', Glob. Plan. Change, in press.

Rind, D.: 1999, 'Complexity and Climate', Science 284, 105-107. 
Sachs, J. P. and Lehman, S.: 1999, 'Subtropical North Atlantic Temperatures 60,000 to 30,000 Years Ago, Science 286, 756-759.

Salas, J. D. and Pielke Sr., R. A.: 2002, 'Stochastic Characteristics and Modeling of Hydroclimatic Processes', Chapter 32 in Potter, T. and Colman, B. (eds.), Handbook of Weather, Climate, and Water, John Wiley and Sons, in press.

Salas, J. D., Obeysekera, J. T. B., and Boes, D. C.: 1981, in Singh, V. P. (ed.), Modeling of the Equatorial Lakes Outflows, in Statistical Analysis of Rainfall and Runoff, Water Resources Publications, Littleton, CO, pp. 431-440.

Sarewitz, D., Pielke Jr., R. A., and Byerly Jr., R.: 2000, Prediction, Science, Decision Making and the Future of Nature, Island Press, Washington, DC, p. 405.

Sarmiento, J. L., Hughes, T. M. C., Stouffer, R. J. (et al.): 1999, 'Simulated Response of the Ocean Carbon Cycle to Anthropogenic Climate Warming', Nature 402, 245-249.

Schellnhuber, H. J.: 1999, 'Earth System Analysis and the Second Copernican Revolution', Nature 402, C19-C26.

Schimel, D., Melillo, J., Tian, H. Q., McGuire, A. D., Kicklighter, D., Kittel, T., Rosenblum, N., Running, S., Thorton, P., Ojima, D., Parton, W., Kelly, R., Sykes, M., Neilson, R., and Rizzo, B.: 2000, 'Contribution of Increasing $\mathrm{CO}_{2}$ and Climate to Carbon Storage by Ecosystems in the United States', Science 287, 2004-2006.

Stocker, T. F. and Schmittner, A.: 1997, 'Influence of $\mathrm{CO}_{2}$ Emission Rates on the Stability of the Thermohaline Circulation', Science 388, 862-865.

Sveinsson, O. G., Salas, J. D., Boes, D. C., and Pielke Sr., R. A.: 2003, 'Modeling of Long Term Variability of Climatic and Hydrologic Processes', J. Hydrometeor. 4, 489-505.

Thompson, A. M. and Cicerone, R. J.: 1986, 'Possible Perturbations to Atmospheric CO, $\mathrm{CH}_{4}$, and OH', J. Geophys. Res. 91, 10853-10864.

Tziperman, E., Stone, L., Cane, M. A., and Jarosh, H.: 1994, 'El Niño Chaos: Overlapping of Resonances between the Seasonal Cycle and the Pacific Ocean-Atmosphere Oscillator', Science 264, 72-74.

Vitusenko, P. M., Mooney, H. A., Lubchenco, J., and Melillo, J. M.: 1997, 'Human Domination of Earth's Ecosystems', Science 277, 494-499.

Vörösmarty, C. J. P., Green, P., Salisbury, J., and Lammers, R. B.: 2000, 'Global Water Resources: Vulnerability from Climate Change Acid Population Growth', Science 289, 284-288.

Watson, A. J. and Lovelock, J. E.: 1984, 'Biological Homeostasis of the Global Rnvironment: The Parable of Daisyworld', Tellus 35, 284-289.

Werth, D. and Avissar, R.: 2002, 'The Local and Global Effects of Amazon Deforestation', J. Geophys. Res. 107, D20, 8087, doi: 10.1029/2001JD000717.

Zhao, M., Pitman, A. J., and Chase, T.: 2000, 'The Impact of Land Cover Change on the Atmospheric Circulation', Clim. Dyn. 17, 467-477.

(Received 11 March 2002; in revised form 1 October 2003) 